\title{
Ecological restoration and effect investigation of a river wetland in a semi-arid region, China
}

\author{
SHIGUO XU, XIN JIANG, YUYU LIU, YANZHAO FU \& QIAN ZHAO \\ Institute of Water and Environmental Research, Faculty of Infrastructure Engineering, Dalian University of Technology, \\ Dalian, 116024, China. \\ sgxu@dlut.edu.cn, yliu@mail.dlut.edu.cn
}

\begin{abstract}
River wetlands are heavily impacted by human intervention. The degradation and loss of river wetlands has made the restoration of river ecosystems a top priority. How to rehabilitate rivers and their services has been a research focus. The main goal of it is to restore the river wetland ecosystems with ecological methods. The Gudong River was selected as a study site in Chaoyang city in this study. Based on the analysis of interference factors in the river wetland degradation, a set of restoration techniques were proposed and designed for regional water level control, including submerged dikes, ecological embankments, revegetation and dredging. The restoration engineering has produced good results in water quality, ecoenvironment, and landscape. Monthly reports of the Daling River show that the water quality of Gudong River was better than Grade III in April 2013 compared with Grade V in May 2012. The economic benefit after restoration construction is 1.71 million RMB per year, about 1.89 times that before. The ratio of economic value, social value and eco-environmental value is 1:4:23.
\end{abstract}

Key words ecological restoration; river wetland; ecological services; benefit evaluation; Gudong River

\section{INTRODUCTION}

Wetland ecosystems are rich in natural resources, provide important ecological services and abundant biomass. The Millennium Ecosystem Assessment showed that about three-fifths of global ecosystem services are being degraded or used unsustainably (MEA, 2005), and more than half of the original wetlands in the world have been lost due to drainage projects and human activities (Mitsch, 2005; Cui et al., 2009). River wetlands are located in the land-river ecotones, which have a higher water level, special vegetation and soil properties, as well as rich biodiversity and are highly productive. Due to excessive exploitation and utilization by humans, the river wetland ecosystem is seriously degenerated, influencing the sustainable development of humans and society. Therefore, it is very necessary to research the ecological restoration of river wetlands with the purpose of protecting them effectively.

However, wetland restoration is more complex than implied by early concepts of ecosystem degradation and restoration (Zedler, 2000). There is no simple solution to restoring and rehabilitating river wetlands, particularly in terms of long-term sustainability (Gumiero et al., 2013). Many wetland restoration activities have been implemented in different inner and coastal areas, with major restoration drivers, such as improvement of wet habitats and related species (Gray et al., 2002; Jin et al., 2008), flood risk, better ecological status and sustainable agricultural activities (Gumiero et al., 2009). Additionally, how to assess the efficiency of wetlands restoration, and define its success, has been a focus of debate (Tong et al., 2007).

Based on the above background, the Gudong River wetland, a small river wetland with special meaning in northeastern China, was selected as a study site. The objectives of this research are to (1) analyse the reasons of river wetlands degradation; (2) study the ecological restoration scheme and design the construction of Gudong River wetland; (3) assess the environmental restoration responses and evaluate the construction benefits. This paper aims to develop a set of techniques and methodologies for ecological restoration of small-scale river wetlands in a unique protected area, and provide a basis which future researchers and decision-makers can use to achieve the main purpose of river wetlands management.

\section{MATERIAL AND METHODS}

\section{Study area}

The Gudong River, a tributary of the Daling River, is located in western Liaoning province of northeastern China. It belongs to the temperate continental climate area. The Gudong River wetland 
$\left(41^{\circ} 366^{\prime} 50^{\prime \prime}-41^{\circ} 37^{\prime} 10^{\prime \prime} \mathrm{N}, 120^{\circ} 34^{\prime} 22^{\prime \prime}-120^{\circ} 34^{\prime} 48^{\prime \prime} \mathrm{E}\right)$ lies in the junction of the Daling River and Gudong River. Historically, with lush aquatic plants and many species of fish, shrimp and waterfowl, the Gudong River wetland was an important transfer station for migratory birds. Also, it provided good water resources to the downstream area (Jinzhou city), and played a positive role in the local eco-environment improvement and climate regulation. Along with its development, the issues of wetland degeneration have become increasingly conspicuous, such as water pollution, vegetation retrogression, soil erosion and biodiversity decline. Therefore, it is necessary and urgent to design the restoration in a practical manner for the Gudong River wetland. Figure 1 shows the location of the study area, covering about $0.45 \mathrm{~km}^{2}$.

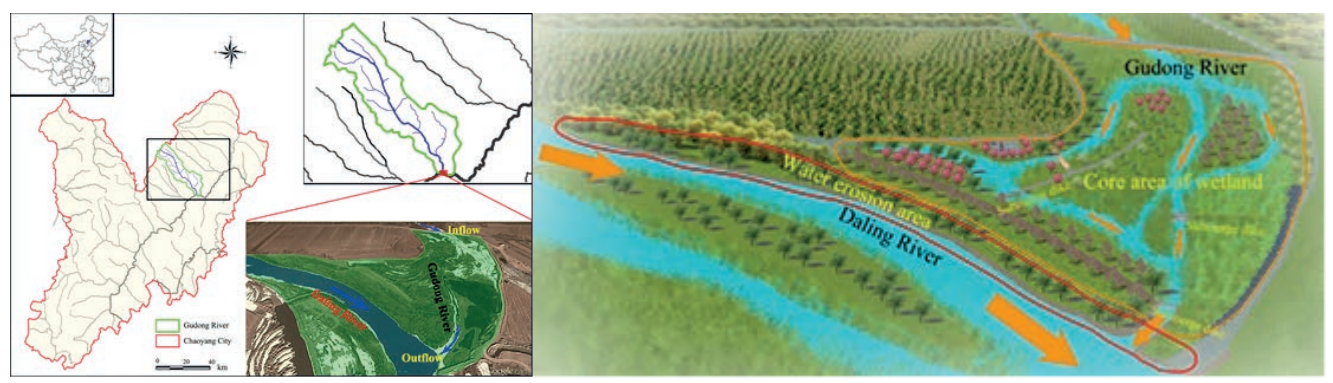

Fig. 1 Location of the Gudong River and river wetland restoration project area (left). Area of flood impact in the Gudong river wetland (right).

The interference factors in the Gudong River wetland degradation are combinations of natural disturbances (e.g. climate changes) and human activities (e.g. pollution and improper development).

Rainfall events with high intensities and short duration play dominant roles in causing disturbance of the wetland stability, such as water front changing, slope instability, soil and water loss and other flood hazards. The Gudong River is heavily polluted by industrial sewage, agricultural production and domestic waste. The runoff carries contaminants into the Gudong River wetland, damages the quality of water and soil and endangers the wildlife.

\section{Restoration design}

The main process of the restoration project is initially designed to increase the self-rehabilitation capacity of the Gudong River wetland ecosystem.

The Gudong River wetland is close to Chaoyang city, less than $10 \mathrm{~km}$ downstream from the urban area, and contains a natural landscape of water, pasture and wildlife. Given this distance, people arrive at this wetland to experience the nature, keep tranquil and get away from the noise and pollution of the city. It is a fun and relaxed place to take exercise and strolls along the riverside, as well as wading in it. There are rich species resources in the river basin, where a lot of paleontological fossils for biological information can be captured. With great ecological, economic and social values, the Gudong River wetland is an important base for science education and ecological research.

The primary target of this design and construction is to: (1) restore the habitat of the river wetlands by maintaining a stable base for the environment, a good performance of water; (2) rehabilitate the biotic community by vegetation recovery and species diversity increase; (3) improve the landscape based on the present situation. When completed, the Gudong River wetland will provide a large ecological place combining both entertainment and humanistic landscape together.

Hydrology is the most important determinant of wetland conditions and dynamics, therefore water management is most often the key-driver to wetland restoration (Gumiero et al., 2013). Due to the steep gradients and illegal sand excavation of the Gudong River channel, there is a great variation of the river bed elevation in the estuary. In the flood season, heavy rainfall runoff means powerful scouring over a wide range of the mouth of the Gudong River. In the non-flood season, the upper stream inflow remains in the estuary area for a short period, leading to scarce vegetation with the character of poor water conditions. Based on the above ecological environment, a set of restoration techniques are proposed by regional water level control. 
The restoration approach of regional water level control refers to pushing water upwards to various levels for different riverbed features by constructing multistage water retaining works, which will increase the water surface area, extend hydraulic retention time, and improve the hygrophilous environment. The restoration design for the Gudong River wetland must follow the criteria of the natural ecology, feasibility, integrity, culture, aesthetics, and sustainable development. The restoration measures for regional water level control contain submerged dikes, ecological embankments, revegetation and dredging.

The submerged dike is a common structure, which has been successfully used in the mid-sized and small rivers of China for raising water level, decreasing the flow speed, promoting silt deposition, and adjusting the riverbed slope $(\mathrm{Xu}, 1980)$. Considering the actual requirements of the Gudong River wetland, three-level submerged dike engineering was designed. The primary structure was to slow the water velocity from the upstream. The secondary submerged dike is mainly focused on raising water level to prolong the hydraulic retention time for wetland flora. The tertiary structure has a major function in preventing the down cutting of the river bed by sand excavation and other human activities. The submerged dike would be submerged by water at high water level, but would be exposed above water at low water level.

Ecological embankment management is an important technology of river restoration. In recent years, with the appeal of the symbiotic relationship between humanity and nature, ecological revetment has become a great method of revetment construction. The construction methods of gabions and willow piles are used in bank protection instead of conventional concrete engineering.

As the left bank of the Daling River, Gudong River is particularly vulnerable to flooding (Fig. 2(a)), gabions (the steel-net covered stones) are designed to protect banks without vegetation cover from being washed away by the river or rainwater (Fig. 2(b)). A mixture of coarse sand, soil and grass seed can be poured into the gabions, or they can be covered with soil and planted to grow green grass and small shrubs, which would produce strong resistance to water washout, provide living space for aquatic animals, and improve the environment of the river ecosystem.
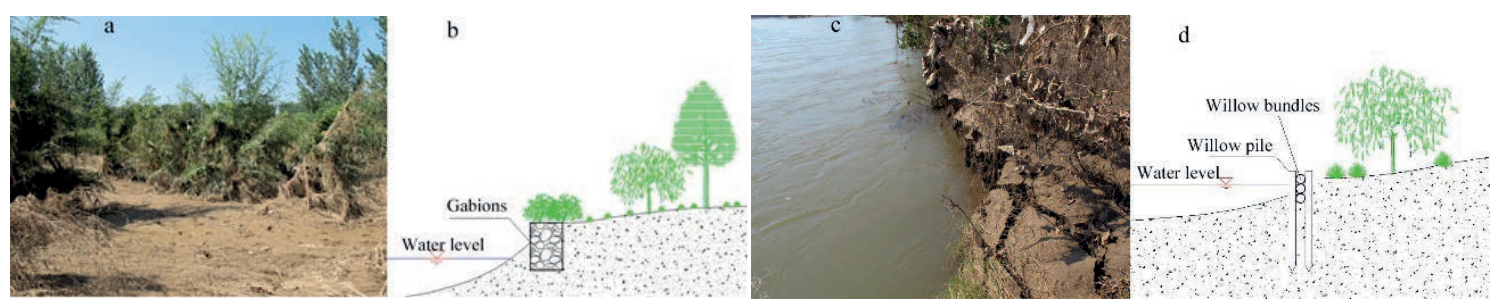

Fig. 2 Flood interference: (a) The vegetation was inundated by floods from Daling River leaving the antiwaterlogging species with poor growth; (b) design of the gabion revetment. Flood interference: (c) River banks collapse due to water washing; (d) design of the willow pile revetment.

Willow pile revetments were applied to consolidate the wetland lines in the estuary of Gudong River (Fig. 2(c), (d)). Special sections requiring high anti-flood measures or some steep slopes should use the multilayer revetment structure with two rows of willow piles. Sheaves of wickers are implanted among the willow piles and will grow up for one year or two, depending on both the river banks' stability and natural landscapes.

Vegetation is considered as an integral part of the river wetland. The spatial structure of different plants must be weighed in the design, so as to create rich layers of wetland landscapes in the satisfactory growing conditions. Figure 1 (right) shows two styles of area affected by flooding erosion, including the water erosion area and core area of wetland. Since the former area is located on the left bank of the Daling River, with strong water scouring in the flood season, plants that are water-tolerant and impact resistance are selected to play a vital role in water and soil conservation, such as poplar, willow, sea-buckthorn and Amorpha fruticosa. The soil in the core area of wetland would be kept almost moist all the year round, so suitable for growth of aquatic plants; and some higher ground can be vegetated with flood resistance trees and shrubs. It is very important to protect the original vegetation and biology in the process of vegetation restoration. 
Dredging is one of the effective engineering measures to control floods, improve the environment and solve problems caused by sand deposited in rivers. According to the actual situation of the study area, the construction wastes and sedimentation in the river channel should be cleared up. Additionally, it is necessary to smooth the streamway by preventing exploration of sand in the Gudong River.

\section{RESULTS}

\section{Environmental restoration monitoring}

To reduce the total amount of pollutant flow into the Daling River and protect the estuarine environment of Gudong River wetland, a set of restoration techniques were designed based on the regional water level control. The restoration project began in May 2012, and ended in November 2012.

Monthly reports of the Daling River show that the water quality of Gudong River estuary monitoring section has verged on Grade III in April 2013, and has been improved from Grade V in May 2012. The restoration has a good effect in removing $\mathrm{BOD}_{5}, \mathrm{NH}_{3}-\mathrm{N}$ and $\mathrm{COD}_{\text {cr. }}$ The most efficient removal rate is of $\mathrm{NH}_{3}-\mathrm{N}$, over 14 times faster than the level of the previous year. The removal of $\mathrm{BOD}_{5}$ is followed by that of $\mathrm{NH}_{3}-\mathrm{N}$, about twice than before. Meanwhile, the concentration of DO increases, which is of great importance for the self-purification process of organic pollutants.

After restoration, the ecological storage level has risen by $0.1 \mathrm{~m}$ due to the set of restoration techniques, forming a larger water area, which creates good hygrophyte conditions and habitat environment for the Gudong River wetland. There is an obvious improvement in the environment and landscape. During the ecologic rehabilitation, vegetation coverage is a major obvious response on wetland. Before restoration, the river wetland was seriously degraded. After restoration, there is a significant landscape with a large plant community and vegetation coverage. The vegetation coverage was more than 55\% in 2013, and could reach 75\% in the year of 2020 (Wang, 2013).

The $0.45 \mathrm{~km}^{2}$ river wetland of the Gudong estuary has been restored. According to responses to the restoration, the benefit is remarkable. The increased water storage of the river wetland supplements groundwater, promoting a balance of extraction and recharge. The vegetation restoration not only improves the local microclimate, but also increases the ecological diversity, helping protect water quality of the Daling River. The restoration has effectively prevented soil erosion and improved the flood control capacity with a good ecological environment.

Post-restoration monitoring is usually limited due to cost, time, and lack of experienced investigators (Cui et al., 2009). The short-term monitoring in this study can supply initial information on the responses of the restoration project. Furthermore, to assess the effect of restoration more precisely, long-term research still needs to be done to provide a series of continual detailed monitoring data in the next years.

\section{River wetland benefit}

Ecosystem services are benefits to humans, including recreational and educational opportunities, aesthetics, spiritual enrichment, and market-based goods and services (Costanza et al., 1997).

River wetland benefit comes from soil, water, nutrients, biocoenosis within the wetlands, as well as abiotic and biotic interaction processes, mainly reflected in three aspects: eco-environmental benefit, economic benefit and social benefit. Table 1 lists the services and methods assessed in the Gudong River wetland.

Eco-environmental service functions are benefits from the river wetland ecosystem for the ecological environment of the local and contiguous zone, and can be assessed in relation to five aspects: gas regulation, flood mitigation, water purification, habitat, and water-soil conservation. Economic benefits mainly come from natural resources in the wetland that can directly produce economic value, such as water resources, and direct production of animals and plants. Social value refers to the benefit to social culture, playing an important role in promoting spiritual civilization, social development and human progress, including the wetland ecotourism, scientific research and culture. 
Table 1 Ecosystem services and functions evaluation for the Gudong River wetland.

\begin{tabular}{|c|c|c|c|}
\hline \multicolumn{2}{|c|}{ Ecosystem valueEcosystem services } & Ecosystem functions & Methods references \\
\hline $\begin{array}{l}\text { Eco- } \\
\text { environmental } \\
\text { value }\end{array}$ & $\begin{array}{l}\text { Gas regulation } \\
\text { Flood Mitigation } \\
\text { Water purification } \\
\text { Habitat } \\
\text { Water-soil conservation }\end{array}$ & $\begin{array}{l}\text { Carbon dioxide fixation, oxygen supply. } \\
\text { Storage and retention of water. } \\
\text { Waste treatment and pollution control. } \\
\text { Habitat for resident and migratory species. } \\
\text { Maintain the soil nutrient to prevent erosion. }\end{array}$ & $\begin{array}{l}\text { Cui 2004; Ouyang et al. } 1999 \\
\text { Jiang et al. } 2007 \\
\text { Xin and Xiao } 2001 \\
\text { Costanza } \text { et al. } 1997 \\
\text { Substitute expense method }\end{array}$ \\
\hline $\begin{array}{l}\text { Economic } \\
\text { value }\end{array}$ & $\begin{array}{l}\text { Production output } \\
\text { Water supply }\end{array}$ & $\begin{array}{l}\text { Production of reeds, grazing and fish. } \\
\text { Farming irrigation water supply. }\end{array}$ & $\begin{array}{l}\text { Ekin et al. } 2006 \\
\text { Market valuation method }\end{array}$ \\
\hline $\begin{array}{l}\text { Social } \\
\text { value }\end{array}$ & $\begin{array}{l}\text { Recreation } \\
\text { Culture }\end{array}$ & $\begin{array}{l}\text { Wetland and eco-tourism } \\
\text { Artistic, educational, and scientific values. }\end{array}$ & $\begin{array}{l}\text { Xie et al. } 2003 \\
\text { Xin and Xiao } 2002\end{array}$ \\
\hline
\end{tabular}

Table 2 The results of wetland benefit value before and after construction (RMB).

\begin{tabular}{llrr}
\hline Ecosystem value & Ecosystem services & Before construction & After construction \\
\hline & Gas regulation & 553443 & 841725 \\
Eco-environmental & Flood mitigation & 26170 & 56320 \\
value & Water purification & 0 & 11033 \\
& Habitat & 0 & 84816 \\
& Water-soil conservation & 274056 & 416809 \\
\hline Economic & Production output & 917 & 28255 \\
value & Water supply & 33000 & 33000 \\
\hline Social & Recreation & 0 & 220991 \\
value & Culture & 17190 & 17190 \\
\hline Total & & 904776 & 1710140 \\
\hline
\end{tabular}

The environment of Gudong river wetland has changed since the restoration construction, with comprehensive benefits adjusting to it. This paper applies a market valuation method, shadow engineering method, substitute expense method, and opportunity cost method to measure the value of Gudong River wetland and Table 2 shows the wetland benefit value before and after construction.

The comprehensive benefit value before the construction of the project was 904.78 thousand RMB a year. Ecosystem services of river wetland for eco-environmental benefit, economic benefit and social benefit are 853.67,33.92 and 17.19 thousand RMB a year, respectively, which means that the eco-environment value of the Gudong River wetland is a priority. Gas regulation and water-soil conservation are the most important services in the eco-environment value, accounting for $61 \%$ and $30 \%$, respectively.

After the restoration, the comprehensive benefit of Gudong river wetland increased to 1.71 million RMB a year, about 1.89 times the original value. The ratio of the three values (economic: social: eco-environmental) is 1:4:23 and the huge eco-environmental value (1.41 million RMB a year) verified the important environmental regulation function of the wetland as "Earth's kidneys". Table 2 also shows that the social benefit has improved by about 14 times, indicating that the social function of Gudong River wetland is better after the restoration. The major services of the evaluated benefit are gas regulation, water-soil conservation and recreation, contributing $49 \%, 24 \%$ and $13 \%$, respectively.

The investment for this restoration in the Gudong River wetland was 8.93 million RMB in 2012. Based on the benefit calculation, about 5 years after the restoration (in 2017), the comprehensive benefit will exceed the amount of investment, bringing further and sustainable benefits.

\section{Discussion}

Wetland restoration is a complex process, which must refer to a wide spectrum of disciplines including ecology, engineering and socio-economics. Meanwhile, the successful construction and management of river wetlands is much more than developing good science and technology; it requires working with landowners, securing funding, supervising staff, and cooperating with policymakers and the public. 
Along with the popularization of the healthy concept of coming back to nature, the wetland attracts growing attention. How to optimally manage and conserve the wetland resources well has now become an important issue to deal with. More propaganda and education about wetland ecoculture should be organized to increase public awareness on biodiversity conservation, environ mental protection, and scientific values of river wetlands, promoting a more stable and sustainable wetland ecosystem.

The construction of river ecological restoration does not mean that the task has been completed. Moreover, it is necessary to strengthen the later-stage management and evaluation of projects to monitor the status of ecological restoration, because it needs a long time for the recovery processes of the wetland ecosystem.

\section{CONCLUSIONS}

Natural disturbance and human activities on wetland ecosystems have raised significant concerns over the last few decades. Focusing on the actual situation of Gudong River wetland, this study finds that the interference factors are flood erosion, industrial and agricultural sewage, household garbage filling, open-pit mining and reclamation. These interferences caused degradation of the ecosystem structure and function in the Gudong River wetland, such as wetland area reduction, water pollution, soil erosion and biodiversity decline. From the perspective of landscape, it appears as a simple ecology landscape type, with decreased spatial heterogeneity, and landscape fragmentation.

The ecological restoration technology of river wetland mainly includes three aspects of the habitat, biocoenosis and landscape: (1) eliminate interference factors and create a good habitat condition; (2) restore plant communities, create habitat and recover biodiversity; (3) construct the wetland as a visually aesthetic space. Based on the analysis of the river wetland degradation and three theories of restoration ecology, landscape ecology and ecological planning, a set of restoration techniques were proposed and designed for regional water level control of the Gudong River wetland, including submerged dikes, ecological embankment, revegetation and dredging.

This short-term monitoring study indicates that the engineering practice has produced good results in water quality, eco-environment, landscape, and flood control. The calculation of benefit to Gudong River wetland shows that the comprehensive value after the restoration is up to 1.71 million RMB a year, about 1.89 times the original value. The benefit after restoration construction is remarkable, with social benefits increased significantly. The Gudong River wetland provides a large ecological place combining leisure, entertainment and humanistic landscapes together.

Acknowledgements This work was financially supported by the National Natural Science Foundation of China (51279022) and the National Key Basic Research Program (2013CB430403).

\section{REFERENCES}

Costanza, R., et al. (1997) The value of the world's ecosystem services and natural capital. Nature 387, 253-260.

Cui, B., et al. (2009) Evaluating the ecological performance of wetland restoration in the Yellow River Delta, China. Ecological Engineering 35(7), 1090-1103.

Cui, L.J. (2004) Evaluation of functions of Poyang Lake ecosystem. Chinese Journal of Ecology 23(4), 47-51 (in Chinese with English abstract).

DEFRA (2004) Making Space for Water: Taking Forward a New Government Strategy for Flood and Coastal Erosion Risk Management in England. DEFRA, London.

Ekin, B., Katia, K. and Phoebe, K. (2006) Using economic valuation techniques to inform water resources management: A survey and critical appraisal of available techniques and an application. Science of the Total Environment 365, 105-122.

Gray, A., et al. (2002) Contrasting functional performance of juvenile salmon habitat in recovering wetlands of the Salmon River Estuary, Oregon, USA. Restoration Ecology 3, 514-526.

Gumiero, B., Boz, B. and Cornelio, P. (2009) River restoration and sustainable agriculture in the Venice Lagoon Basin: the Nicolas project. In: Eulisse, E., Hemmami, M. and Koopmanschap, E. (eds), Sustainable Use of Water in Agriculture. Water Civilization International Centre, Marie Curie actions, Treviso Italy, pp. 43-52.

Gumiero, B., et al. (2013) Linking the restoration of rivers and riparian zones/wetlands in Europe: Sharing knowledge through case studies. Ecological Engineering 56, 36-56.

Jiang, M., et al. (2007) Flood mitigation benefit of wetland soil: A case study in Momoge national reserve in China. Ecological Engineering 61, 217-223.

Jin, C.H. (2008) Biodiversity dynamics of freshwater wetland ecosystems affected by secondary salinisation and seasonal hydrology variation: a model-based study. Hydrobiologia 1, 257-270. 
Lü, S.B., Xu, S.G. and Feng, F. (2012) Floodwater utilization values of wetland services-a case study in Northeastern China. Natural Hazards and Earth System Science 12(2), 341-349.

Millennium Ecosystem Assessment (2005) Ecosystems and Human Well-Being: Synthesis. Island Press, Washington, DC.

Mitsch, W.J. (2005) Wetland creation, restoration, and conservation: a wetland invitational at the Olentangy River Wetland Research Park. Ecological Engineering 24 (4), 243-251.

Ouyan, Z.Y., Wang, X.K. and Miao, H. (1999) A primary study on Chinese terrestrial ecosystem services and their ecologicaleconomic values. Acta Ecologica Sinica 19, 607-613 (in Chinese with English abstract)

Tong, C., et al. (2007) Ecosystem service values and restoration in the urban Sanyang wetland of Wenzhou, China. Ecological Engineering 29(3), 249-258.

Xin, K. and Xiao, D.N. (2002) Wetland ecosystem service valuation-a case research on Panjin area. Acta Ecologica Sinica 22, 1345-1349 (in Chinese with English abstract)

Xu, X.Q. (1980) Submerged dikes in channel. China Communications Press, Beijing (in Chinese).

Zedler, J.B. (2000) Progress in wetland restoration ecology. Trends in Ecology \& Evolution 15(10), 402-407. 